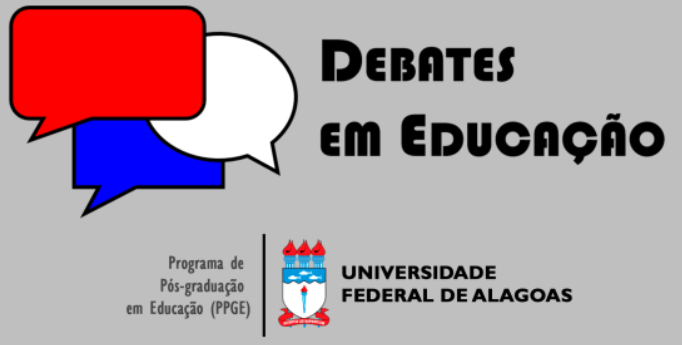

ISSN Eletrônico 2175-6600

Vol. 12 | Número Especial 2 | 2020

Elmo de Souza Lima

9 i

Universidade Federal do Piauí (UFPI) elmolima@gmail.com

\section{EDUCAÇÃO DO CAMPO NO CONTEXTO DO SEMIÁRIDO: MOVIMENTOS DE RESISTÊNCIA E TRANSGRESSÃO PEDAGÓGICA}

\section{RESUMO}

Este trabalho tem o propósito de discutir sobre as estratégias políticas e pedagógicas utilizadas pelas escolas do campo na construção de projetos educativos que favoreçam a formação crítica, a partir do processo de desvelamento da realidade social. Através da pesquisa-ação, desenvolvemos um processo de problematização coletiva acerca das práticas educativas com o intuito de fomentar alternativas pedagógicas associadas aos princípios da educação do campo. Os diálogos críticos estabelecidos com os educadores sobre os projetos educativos da escola possibilitaram o desenvolvimento de atividades interdisciplinares, intervenções e mobilizações sociais que demonstram uma atitude de "transgressão pedagógica", voltada à construção coletiva do conhecimento, à compreensão crítica do campo e ao protagonismo dos jovens.

Palavras-chave: Educação do campo. Prática educativa. Transgressão pedagógica.

\section{RURAL EDUCATION IN THE SEMIARID CONTEXT: RESISTANCE MOVEMENTS AND PEDAGOGICAL TRANSGRESSION}

\begin{abstract}
This work aims to discuss the political and pedagogical strategies used by rural schools in the construction of educational projects that favor critical training, based on the process of unveiling the social reality. Through action research, we developed a process of collective problematization about educational practices in order to foster pedagogical alternatives associated with the principles of rural education. The critical dialogues established with educators about the school's educational projects, enabled the development of interdisciplinary activities, interventions and social mobilizations that demonstrate an attitude of "pedagogical transgression", aimed at the collective construction of knowledge, critical understanding of the field and protagonism of young people.
\end{abstract}

Keywords: Rural education. Educational practice. Pedagogical transgression.

Submetido em: 25/04/2020

Aceito em: 04/08/2020

Publicado em: 30/12/2020

d. http://dx.doi.org/l0.28998/2175-6600.2020v12nEsp2p 193-212 


\section{INTRODUÇÃO}

As práticas educativas desenvolvidas nas escolas do campo trazem as marcas históricas de uma tradição pedagógica conservadora, caracterizada pela fragmentação, hierarquização e a descontextualização do conhecimento e pela negação dos saberes sociais construídos pelos educandos. São experiências construídas a partir da racionalidade pedagógica instrumental, associada à "educação bancária", que pouco contribui na produção de conhecimentos que favoreçam a compreensão crítica e o reconhecimento dos educandos enquanto sujeitos históricos (FREIRE, 2005).

Diante desse contexto, organizamos um projeto de investigação que pudesse, por um lado, compreender como são instituídas as práticas educativas nas escolas do campo; e, por outro, refletir sobre as alternativas teórico-metodológicas voltadas ao desenvolvimento de projetos educativos que dialoguem com as experiências e os sabres dos camponeses e possibilitem a construção de conhecimentos que problematizem esse contexto de exclusão e de injustiças sociais que permeia a realidade do campo, apontando possibilidades de transformação social.

A investigação foi desenvolvida na Escola Municipal Liberato Vieira, na comunidade Brejo da Fortaleza, no município de Ipiranga-PI, no período de 2015 e 2016, envolvendo 12 educadoras que atuavam na instituição, com base nos pressupostos teórico-metodológicos da pesquisa-ação crítica, discutidos por Franco (2005). A escolha desta instituição de ensino justifica-se pelo fato de darmos continuidade a nossa pesquisa de doutorado em educação realizada em 2014 na referida escola, quando tivemos a oportunidade de vivenciar inúmeras aprendizagens coletivas associadas à construção de projetos educativos comprometidos com os princípios da educação do campo, num diálogo com os pressupostos teóricos e epistemológicos das teorias críticas da educação, a partir das contribuições da pedagogia freireana (FREIRE, 2005).

A partir das Rodas de Diálogos ${ }^{1}$, desencadeamos os processos de reflexão e problematização das práticas educativas por meio do diálogo entre as educadoras ${ }^{2}$ e outros sujeitos envolvidos no trabalho educativo, com o propósito de evidenciar os avanços e as lacunas das práticas educativas, considerando os princípios defendidos nas diretrizes políticas e pedagógicas da Educação do Campo (BRASIL, 2002).

A opção pela pesquisa-ação justifica-se pelos pressupostos epistemológicos que orientam a produção coletiva do conhecimento, que rompe com a lógica colonizadora instituída na construção do conhecimento científico vinculado aos preceitos da ciência moderna, colocando os diferentes sujeitos

\footnotetext{
' O trabalho com as Rodas de Diálogos fundamenta-se nos pressupostos políticos e epistemológicos dos "Círculos de Cultura", desenvolvidos por Paulo Freire nas experiências de educação popular no Brasil. São espaços de problematização, dialogicidade e troca de experiência entre os sujeitos, visando ao desenvolvimento da práxis educativa. (FREIRE, 1992).

2 Fizemos a opção de utilizar o termo "educadoras" quando nos referimos aos sujeitos da pesquisa tendo em vista que todas eram do sexo feminino. Em algumas atividades de investigação, contamos com a colaboração de educandos e suas famílias.
} 
como protagonistas e produtores de conhecimentos, dando visibilidade aos conhecimentos e saberes construídos no contexto das experiências sociais e profissionais (LIMA, 20I5).

Este trabalho tem o propósito de discutir as estratégias políticas e pedagógicas utilizadas pelas escolas do campo na construção de projetos educativos que favoreçam à formação crítica dos educandos, a partir da valorização das experiências sociais dos camponeses e de apropriação crítica do conhecimento escolar, implicando uma relação de desvelamento da realidade social, política e econômica do mundo rural.

\section{AS ESTRATÉGIAS DE LUTAS E RESISTÊNCIAS DOS CAMPONESES: OS REFERENCIAIS HISTÓRICOS DA EDUCAÇÃO DO CAMPO}

O território camponês foi marcado historicamente no Brasil pelas mais variadas formas de violências físicas e culturais, que tiveram início com a colonização portuguesa, a partir da apropriação indevida da terra e a expulsão dos povos indígenas, bem como do processo de escravização de negros e índios para atender aos interesses econômicos dos colonizadores.

Esse projeto político de dominação implementado pelos colonizadores, caracterizado pela violência, exclusão e a expropriação das riquezas, teve continuidade com a ascendência das oligarquias agrárias e o fortalecimento do coronelismo no Nordeste, a partir da República Velha, no final do século XIX, tornando-se uma marca histórica da vida social e política no contexto do semiárido 3 brasileiro. Este cenário de completo abandono da população, marcado pela proliferação da miséria e da fome, fez com que o coronelismo ganhasse força no meio rural, obrigando os trabalhadores excluídos a submeterem-se às condições de semiescravidão para garantir as condições de sobrevivência

Por essa razão, a miséria se constituiu uma estratégia de dominação política que se perpetuou pelo sertão nordestino, refletindo fortemente no modelo de Estado em construção e no projeto de desenvolvimento concebido pelas elites conservadoras, associado às práticas assistencialistas e clientelistas, que reforçavam a lógica da dependência e da submissão aos coronéis (LEAL, 1997).

Neste contexto, a subtração do direito à educação aos excluídos constituiu-se uma estratégia de dominação política e cultural das oligarquias agrárias, pois quanto menos conhecimento tivesse a população, maior seria o controle ideológico exercido pelas elites conservadoras sobre os camponeses.

Este cenário de exclusão fez surgir os movimentos de resistências (Canudos, Contestado, Cangaço, entre outras) que evidenciavam a revolta dos camponeses com as condições históricas de

\footnotetext{
${ }^{3}$ O semiárido brasileiro é uma região de clima seco, marcada por irregularidades de chuvas, tendo a caatinga como vegetação predominante. Envolve I. 189 municípios onde vivem mais de 25 milhões de pessoas, que representam I2\% da população brasileira. Concentra mais da metade da população brasileira em situação de extrema pobreza.
} 
opressão instituídas pelas elites escravocratas. Neste contexto de luta, as Ligas Camponesas tiveram um papel importante, entre as décadas de 1940 e 1960, na mobilização, formação e organização das lideranças que assumiram a luta no nordeste brasileiro em defesa da classe trabalhadora do campo.

A organização política iniciada com as Ligas Camponesas difundiu as sementes que, a partir da década de 1970, fizeram brotar os movimentos sociais do campo, que protagonizaram as principais lutas políticas empreendidas, nas décadas de 1980 e 1990, contra as oligarquias agrárias, representadas pelos velhos coronéis, que se perpetuaram nos sertões, e as novas elites agrárias que emergiram com a força do agronegócio. As lutas sociais dos movimentos estão pautadas na defesa da reforma agrária e das políticas de apoio à agricultura camponesa, no combate ao latifúndio e às políticas de exploração e destruição do meio ambiente disseminada pelo agronegócio.

Se, por um lado, temos o latifúndio como principal marca da exclusão da população camponesa, com a negação do direito à terra como princípio de vida, por outro, temos a ausência de políticas públicas que garantam as condições mínimas de sobrevivência no campo, voltadas para a consolidação de projetos de reforma agrária, que possibilitem a democratização da terra e condições de produção sustentável, com o fortalecimento da agroecologia e da produção de alimentos saudáveis.

Nesse processo de organização da classe trabalhadora, os movimentos sociais sentiram a necessidade de investir em projetos educativos voltados ao desenvolvimento da consciência crítica dos camponeses, bem como à compreensão crítica do contexto sócio-histórico, político e cultural no qual estavam inseridos, marcados pela exclusão e opressão.

No final da década de 1950, os movimentos sociais iniciam as experiências no campo da educação popular ${ }^{4}$, tendo os fundamentos marxistas e a pedagogia freireana como principais referenciais políticos e teórico-metodológicos associados à problematização da realidade com o intuito de fomentar o desenvolvimento da consciência crítica. Neste caso,

[...] a Educação Popular constitui uma prática referida ao fazer e ao saber das organizações populares, que busca fortalecê-la enquanto sujeitos coletivos, e assim, contribuir através de sua ação-reflexão ao necessário fortalecimento da sociedade civil e das transformações requeridas, tanto para a construção democrática de nossos países, como para o desenvolvimento econômico com justiça social. (CEAAL, 1994, p. 73).

As experiências de educação popular se expandiram entre diversos movimentos e organizações sociais do campo, contribuindo na formação crítica dos camponeses, evidenciando seu papel político enquanto sujeito histórico, bem como no fortalecimento dos movimentos sociais, tendo em vista a dimensão política, pedagógica e metodológica desta proposta de educação. Segundo Freire ( I 980, p. I I0),

\footnotetext{
${ }^{4}$ A educação popular surgiu, no Brasil, a partir das ideias de Paulo Freire e está associada aos princípios político-pedagógicos e metodológicos utilizados pelas organizações sociais, nas suas dinâmicas de formação e mobilização social, com o intuito de possibilitar a construção coletiva de conhecimentos e saberes que desenvolvam nas pessoas a capacidade de análise crítica sobre a realidade, bem como propiciem o aprimoramento das estratégias de luta que favoreçam a construção de novos processos de emancipação e transformação social.
} 
essa educação possibilita que o "[...] educador e o povo se conscientizem através do movimento dialético entre a reflexão crítica sobre a ação anterior e a subsequente no processo de luta".

Por meio dos projetos de educação popular, os movimentos sociais compreenderam a importância da formação crítica dos trabalhadores para a construção de um projeto alternativo de sociedade, pautado na justiça social, fraternidade e sustentabilidade. Por isso, buscaram sistematizar as experiências de educação popular com o intuito de consolidar um projeto de educação dos jovens do campo pensado a partir das demandas sociais, políticas econômicas e culturais desse território.

A partir das contribuições da pedagogia freireana, os movimentos sociais construíram uma proposta teórico-metodológica que refletisse um modo de educar e conhecer o mundo, tendo os sujeitos do campo como protagonistas deste processo de apropriação e produção do conhecimento (FREIRE, 2005). Um projeto de educação que partisse das experiências político-organizativas dos camponeses, possibilitando uma articulação entre os conhecimentos construídos a partir da práxis dos movimentos sociais com aqueles produzidos no âmbito da ciência, cultura e das artes.

Com base nos projetos de educação popular, os movimentos sociais passaram a questionar o modelo de "educação rural", concebido a partir do contexto urbano e oferecido de modo precário aos povos do campo, desconsiderando as especificidades sociais, culturais e políticas daquele território. $\mathrm{Na}$ visão dos movimentos, são propostas educativas que negam os saberes e as experiências construídas pelos camponeses, na sua relação com o mundo do trabalho e da cultura, e produzem um tipo de conhecimento deslocado do contexto sociocultural e das experiências coletivas, portanto um conhecimento que traz poucas contribuiç̧̃̃es para o desenvolvimento de outro projeto de sociabilidade justo e sustentável.

O modelo de "educação rural" contribuiu para que se perpetuassem as desigualdades sociais e as relações de dependência no campo, na medida em que ofereceu um saber precarizado, atrelado ao desenvolvimento de competências básicas necessárias à inserção dos trabalhadores nas atividades produtivas que emergiam com a modernização das grandes propriedades rurais. Além disso, segundo Freitas (201 I, p. 37), "reforçou a imagem negativa dos camponeses e de seu estilo de vida, estimulandoos a abandonar o campo buscando ascensão social nos centros urbanos".

Concebida a partir dos interesses do capitalismo agrário, a educação rural foi instituída a partir dos ideais de modernidade que nega os modos de vida construídos a partir dos referenciais culturais e políticoorganizativos dos camponeses, baseado na produção familiar, na economia solidária e cooperativa. Dentro desse contexto, os modos de produção e organização sociais dos camponeses são considerados atrasados e subdesenvolvidos e precisam ser substituídos pelos ideais que norteiam as relações sociais e produtivas propostas pela racionalidade capitalista.

Para Fernandes (2006, p. 37), a educação rural foi concebida com o propósito de difundir os princípios do capitalismo agrário, reforçando a lógica de dominação política e ideológica das oligarquias no 
território rural brasileiro. Assim, "a Educação Rural vem sendo construída por diferentes instituições a partir dos princípios do paradigma do capitalismo agrário, em que os camponeses não são protagonistas do processo, mas subalternos aos interesses do capital”.

Contrapondo-se ao modelo de "educação rural", os movimentos sociais buscaram construir o projeto de "educação do campo", concebido a partir das experiências sociais, políticas e culturais dos camponeses, principalmente das atividades de formação e mobilização social, instituídas através dos projetos de educação popular, vinculadas às matrizes teóricas e pedagógicas que alimentam as lutas sociais em favor da liberdade e da emancipação.

Neste contexto de luta em defesa da educação do campo, a I Conferência Nacional por uma Educação Básica do Campo, realizada em 1998, Luziânia - Goiás, tornou-se um marco histórico na construção dos referenciais políticos e pedagógicos da educação do campo no Brasil. Com a primeira Conferência, a "Articulação Nacional Por uma Educação do Campo" 5 assumiu a tarefa de sistematizar as Diretrizes políticas e pedagógicas do projeto de educação do campo, que têm a realidade e a cultura dos sujeitos como ponto de partida e de chegada dos processos educativos.

O projeto de educação do campo, concebido a partir das experiências dos movimentos sociais do campo, traz em seu arcabouço teórico-metodológico um conjunto de princípios políticos associados à humanização e emancipação dos sujeitos e à transformação do modelo de sociabilidade, excludente, injusto e desigual, instituído historicamente nos territórios rurais, a partir da lógica do capitalismo neoliberal, representado pelo agronegócio.

Inspirados nos ideais políticos da pedagogia socialista (PISTRAK, 2003), da Pedagogia do Movimento (CALDART, 2000) e do pensamento freireano (FREIRE, 2005), os movimentos sociais do campo assumiram o desafio de construir outros referenciais teóricos e metodológicos que deem conta de produzir novos conhecimentos numa relação de diálogo com as práticas sociais, políticas e organizativas dos povos do campo, de modo que estes conhecimentos ajudem na compreensão crítica do campo com suas especificidades, contradições e potencialidades, tendo os sujeitos sociais como seus protagonistas. $\mathrm{Na}$ visão de Arroyo (2003, p. 43),

Os movimentos nos colocam o difícil diálogo entre os conhecimentos socialmente construídos sobre dimensões do viver humano muito mais conflituosa do que as áreas do conhecimento e os currículos por vezes supõem. Nos advertem que a diversidade de sujeitos sociais, de protagonistas da construção da história, da cidade, do campo, tem formas diversas de conhecer a cidade, o campo e a história da qual participam.

autor acrescenta que os movimentos sociais reeducam o pensamento educacional, a teoria pedagógica, na medida em que põe em xeque o pensamento pedagógico que nega os povos do campo

\footnotetext{
${ }^{5}$ A "Articulação Nacional Por Uma Educação do Campo" é uma rede que congrega diversos movimentos e organizações sociais, instituições e universidades comprometidas com as lutas em defesa da educação do campo. Foi criada na primeira Conferência Nacional por Uma Educação Básica do Campo realizada em julho de 1988, em Luziânia, Goiás.
} 
enquanto sujeitos históricos, situando suas lutas no apêndice da história. Os movimentos sociais articulam coletivos nas lutas pelas condições de produção da existência popular mais básica e, neste processo, se descobrem e se aprendem como sujeitos de direitos, como seres capazes de construir novas perspectivas de vida (ARROYO, 2003).

Diante desse contexto, Silva (2006, p. 88) argumenta que os movimentos sociais como sujeitos coletivos constroem novas concepções e práticas educativas que possibilitam "a (re) criação de relações educativas e da própria ideia do que seja a educação". A partir dessas concepções, redimensionam-se as relações entre educador e educando, ao se incorporar na escola uma prática libertadora que fomenta a reflexão crítica e a problematização da realidade, tendo os educandos como protagonistas do processo de construção do conhecimento.

Os projetos educativos construídos a partir dessa pedagogia do movimento buscam estabelecer uma relação diferente com o conhecimento e a realidade, de forma que o mundo escolar não se dissocia do mundo dos fatos, da vida, das lutas cotidianas. São práticas que incorporam as linguagens artísticas e os referenciais da cultura e da memória dos povos do campo, fomentando o uso da imaginação, da criação e de meios motivadores para a reconstrução de identidades, reafirmando suas relações de pertencimento e inserção social no contexto do campo. (SILVA, 2006).

Os diálogos estabelecidos entre os movimentos sociais do campo e o Ministério da Educação, por meio da Secretaria de Educação Continuada, Alfabetização, Diversidade e Inclusão (SECADI), possibilitaram a construção do documento "Referências Nacionais para uma Educação do Campo", que define os seis princípios pedagógicos que deverão subsidiar a formulação de políticas de Educação do Campo em âmbito nacional (BRASIL, 2005):

I. O Princípio Pedagógico do papel da escola enquanto formadora de sujeitos articulada a um projeto de emancipação humana defende que os projetos educativos desenvolvidos nas escolas do campo reconheçam as especificidades dos camponeses e o protagonismo destes sujeitos na construção de conhecimentos e saberes associados às diferentes possibilidades de produção da vida neste território. Em virtude disto, propõe que as instituições de ensino promovam atividades associadas à produção crítica do conhecimento, ao exercício da autonomia e da emancipação humana.

II. O Princípio Pedagógico da valorização dos diferentes saberes no processo educativo compreende que o campo é constituído por diversos grupos sociais, permeado por diferenças sociais, étnicas e culturais que precisam ser reconhecidas e valorizadas no contexto das atividades pedagógicas. Desse modo, as estratégias teórico-metodológicas utilizadas nas escolas devem garantir o reconhecimento dos diferentes conhecimentos e saberes produzidos pelos sujeitos a partir de 
suas experiências neste território. Além disso, precisam criar espaços para as trocas de experiências e saberes, bem como para os diálogos entre os saberes da experiência com os demais conhecimentos vinculados às áreas do currículo escolar, possibilitando uma compreensão crítica da realidade.

III. O Princípio Pedagógico dos espaços e tempos de formação dos sujeitos da aprendizagem compreende que a construção do conhecimento ocorre em diferentes espaços sociais, políticos e culturais, portanto, cabe à escola criar as diferentes estratégias pedagógicas para a sistematização dos aprendizados construídos pelos educandos nos diferentes contextos de aprendizagens, possibilitando uma articulação fecunda entre as aprendizagens construídas nos espaços sociais com aqueles propostas das diferentes áreas do conhecimento.

IV. O Princípio Pedagógico do lugar da escola vinculada à realidade dos sujeitos defende que a escola deve estar inserida na realidade do campo, vinculada aos projetos sociais, políticos e organizativos dos sujeitos, atuando a partir das necessidades, dos sonhos e das utopias dos camponeses. Por essa razão, os projetos educativos devem auxiliá-los na compreensão crítica da realidade e na construção de conhecimentos que potencializem as estratégias de transformação social.

V. O Princípio Pedagógico da educação como estratégia para o desenvolvimento sustentável compreende que a educação tem a função de auxiliar os grupos sociais na construção das alternativas de desenvolvimento sustentável, concebidas coletivamente a partir do estudo sobre as potencialidades dos diferentes territórios rurais. Neste caso, é fundamental que a escola mobilize conhecimentos e práticas que favoreçam a compreensão das potencialidades locais e a utilização de tecnologias sociais voltadas à implementação de políticas de desenvolvimento concebidas a partir da organização comunitária e dos princípios da sustentabilidade, da justiça e do bem-estar social e econômico.

VI. O Princípio Pedagógico da autonomia e colaboração entre os sujeitos do campo e o sistema nacional de ensino defende que as políticas de educação do campo sejam concebidas e implementadas a partir da articulação e colaboração entre os movimentos sociais do campo e os estados e municípios, respeitando as demandas e especificidades de cada região ou território.

Com base nestes princípios pedagógicos, os movimentos sociais vêm estabelecendo os diálogos com as universidades, os estados e os municípios com o propósito de possibilitar que as escolas do campo possam conceber os projetos educativos, a organização curricular e o modelo de gestão pedagógica, considerando a temporalidade e os saberes dos educandos, as experiências políticas e organizativas das comunidades, buscando articular os diferentes conhecimentos construídos historicamente neste território 
com os conhecimentos produzidos na área da ciência, da arte e da tecnologia que possam contribuir na construção das alternativas de desenvolvimento para os territórios rurais.

As lutas empreendidas pelos movimentos sociais, a partir da década 1990, trouxeram conquistadas positivas na área das políticas públicas de educação do campo e da formação de educadores para atuar nos territórios rurais. Dentre estas conquistas, podemos destacar o arcabouço legal instituído no Brasil reafirmando o direito dos povos do campo a uma política de educação do/no campo, a exemplo das Diretrizes Operacionais da Educação Básica para as Escolas do Campo, promulgada em 200 I, que trazem um conjunto de preocupações relacionadas ao:

[...] reconhecimento e valorização da diversidade dos povos do campo, a formação diferenciada de professores, a possibilidade de diferentes formas de organização da escola, a adequação dos conteúdos às peculiaridades locais, o uso de práticas pedagógicas contextualizadas, a gestão democrática, a consideração dos tempos pedagógicos diferenciados, a promoção, através da escola, do desenvolvimento sustentável e do acesso aos bens econômicos, sociais e culturais (BRASIL, 2007, p. 17).

As Diretrizes Operacionais, além de estabelecerem novos princípios políticos e pedagógicos para as escolas do campo, que atendem aos interesses e às necessidades dos jovens camponeses, criaram um novo marco legal, obrigando, em seu artigo 13, que os sistemas de ensino reconstruam seus projetos de formação com base nos seguintes componentes:

1 - estudos a respeito da diversidade e o efetivo protagonismo das crianças, dos jovens e dos adultos do campo na construção da qualidade social da vida individual e coletiva, da região, do país e do mundo;

II - propostas pedagógicas que valorizem, na organização do ensino, a diversidade cultural e os processos de interação e transformação do campo, a gestão democrática, o acesso ao avanço científico e tecnológico e respectivas contribuições para a melhoria das condições de vida e a fidelidade aos princípios éticos que norteiam a convivência solidária e colaborativa nas sociedades democráticas (BRASIL, 2002).

Nessa perspetiva, os marcos legais instituídos na área da educação do campo trouxeram contribuições relevantes para consolidação de diferentes programas e projetos que compõem as políticas de educação do campo no Brasil. No entanto, muitos são os desafios que precisam ser enfrentados no âmbito das secretarias estaduais e municipais de educação, e nas próprias instituições de ensino, para que estas políticas concebidas em nível nacional possam se materializar no chão das escolas, garantindo o direito efetivo das crianças de ter uma educação de qualidade, concebida a partir da daquele território e comprometida com a transformação da realidade de exclusão social e econômica na qual estão imersas milhares de famílias camponesas. 


\section{AS PRÁtICAS EDUCATIVAS DAS ESCOLAS DO CAMPO: AS POSSIBILIDADES DE TRANSGRESSÃO PEDAGÓGICA}

A transformação das práticas educativas implica a realização de reflexões que evidenciem, por um lado, o processo de dominação política, econômica e cultural instituído pelo modelo de desenvolvimento capitalista, caracterizado pela exclusão, violência e a negação dos direitos sociais; por outro, as relações existentes entre o projeto de desenvolvimento, concebido a partir do agronegócio, com as políticas e práticas educativas desenvolvidas no campo, associadas à reprodução de conhecimentos e valores que respaldam o modelo de desenvolvimento capitalista.

Por essa razão, as reflexões construídas nas Rodas de Diálogo voltaram-se à problematização das práticas educativas da Escola Municipal Liberato Vieira, buscando compreender como são constituídos os projetos educativos, quais suas vinculações com as práticas sociais dos educandos e como as experiências educativas dialogam com os saberes construídos pelos sujeitos a partir da sua inserção do universo social, político, econômica e cultural do campo.

Neste processo, as educadoras puderam ampliar a compreensão acerca da educação, concebendo-a implicada às relações sociais, políticas e culturais instituídas no mundo rural, condicionada pelo projeto de sociabilidade capitalista neoliberal. Ao problematizar as práticas educativas, as vinculações entre os princípios políticos que dão sustentação às experiências educativas com aqueles propagados pelo pensamento neoliberal foram sendo evidenciadas, demonstrando como as ideologias capitalistas influenciam as políticas e as teorias pedagógicas que definem o tipo de conhecimento, valores e ideologias reforçadas nos projetos educativos.

Com base nas contribuições de Freire (2005), organizamos o trabalho de investigação desenvolvido com as educadoras com o intuito de estabelecer, inicialmente, uma relação entre os projetos educativos em desenvolvimento na Escola e os modelos de sociabilidades em disputa no campo. Dentro deste contexto, as reflexões foram construídas a partir de três dimensões:

l) O processo de "problematização e apreensão da realidade sócio-histórico e cultural", dedicado à reflexão sobre o contexto sócio-histórico, político e econômico dos povos do campo, com o intuito de compreender, por um lado, os desafios enfrentados pelos camponeses na luta pela produção da vida e, por outro, de visualizar as alternativas de construção de outros modelos de sociabilidade concebidos pelos movimentos sociais associados ao desenvolvimento de projetos alternativos pautados na organização coletiva, no princípio da equidade e sustentabilidade. 
2) $\bigcirc$ processo de "problematização e apreensão do projeto educativo" em desenvolvimento na escola, construído a partir da imersão crítica nas práticas educativas desenvolvidas pelas educadoras, buscando evidenciar os pressupostos teóricos e epistemológicos que orientam estas atividades, bem como o desvelamento dos princípios e fins políticos.

3) A construção de alternativas teórico-metodológicas associadas ao desenvolvimento de práticas educativas que favoreçam a construção coletiva do conhecimento, tendo a realidade sociocultural dos educandos como ponto de partida para a compreensão crítica do mundo, concebida a partir dos referenciais políticos da educação do campo.

Este trabalho de problematização das condições sócio-históricas, políticas e econômicas possibilitou uma compreensão mais ampla dos reais problemas do campo, compreendendo-os enquanto "situaçõeslimites" a serem superadas pelos camponeses através das lutas políticas voltadas à construção de outro projeto de sociabilidade em contraposição ao modelo capitalista.

A partir destas reflexões sobre a realidade socio-histórica e cultural do campo, foi possível resgatar os elementos teóricos que ajudaram a pensar num modelo de educação em sintonia com outra proposta de sociabilidade. Uma educação que parta do reconhecimento dos saberes dos grupos sociais e seus projetos políticos, possibilitando experiências educativas voltadas à construção de conhecimentos comprometidos com o empoderamento dos educandos.

Nos espaços de diálogos e trocas de experiências contruídos com as educadoras, tivemos a preocupação de estabelecer uma articulação crítica entre as experiências vivenciadas na escola e o arcabouço teórico-metodológico associado às teorias críticas da educação (FREIRE, 2005; GIROUX, 1986; ARROYO, 2003; CALDART, 2000; entre outros) que dão sustentação à concepção de educação do campo, buscando evidenciar os pressupostos políticos e pedagógicos que orientam as práticas educativas das escolas. Com este trabalho, as educadoras apropriaram-se dos princípios e valores e das intencionalidades políticas implícitas nas práticas educativas implementadas no contexto da educação do campo.

Esse debate em torno dos princípios políticos que dão sustentação aos projetos educativos foi fundamental para que as educadoras compreendessem que todo ato educativo é constituído de uma intencionalidade política, portanto, o modo como organizamos os espaços pedagógico, os tempos das atividades, os conteúdos escolares, as regras de convivência e as relações entre os educando estão permeados por implicações políticas e ideológicas, que refletem e/ou são respaldadas nos princípios e valores que condicionam o nosso modo de ser e estar no/com o mundo (FREIRE, 2005).

Os debates realizados sobre as bases teóricas e epistemológicas que dão sustentação ao projeto de educação do campo foram importantes para questionarmos os princípios e valores que fundamentam 
o modelo de educação em desenvolvimento nas escolas do campo associados à pedagogia clássica, portanto, ao modelo de educação bancária, centrado na utilização de procedimentos didáticos e pedagógicos que primam pela reprodução acrítica e descontextualizada do conhecimento, ignorando a realidade sócio-histórica dos sujeitos e a diversidades de experiências, conhecimentos e saberes produzidos na relação dos sujeitos sociais com/no mundo.

Com o intuito de desconstruir esse modelo de educação urbanocêntrico, realizamos alguns estudos acerca dos princípios que fundamentam as experiências de educação implementados nas escolas do campo, demonstrando os limites implícitos nestes projetos de formação. Em contraposição, apresentamos os referenciais políticos da educação do campo, destacando as estratégias pedagógicas construídas a partir das experiências de educação popular, através da pesquisa participante, das rodas de diálogos, das trocas e da construção coletiva do conhecimento, das místicas, dentre outras, que constituem a riqueza pedagógica e metodológica deste modelo de educação construído pelos movimentos sociais do campo. São procedimentos didáticos e pedagógicos que possibilitam a imersão crítica do sujeito no mundo, a partir do desenvolvimento da postura crítica dos educandos, colocando-os como protagonista do processo de construção do conhecimento e de desvelamento do mundo.

Na medida em que formos nos apropriando coletivamente das categorias teóricas e dos princípios políticos que fundamentam a concepção de educação do campo, buscamos organizar atividades educativas que permitiram a vivência teórico-prática daquela proposição, com o desenvolvimento de atividades educativas que se constituíram como práxis educativa, enquanto síntese das experiências de reflexão crítica nas quais estávamos imersos.

\section{I A construção de práticas educativas interdisciplinares}

Com base nos debates realizados nas Rodas de Diálogo, as educadoras compreenderam os limites políticos e pedagógicos das práticas educativas desenvolvidas da Escola Municipal Liberato Vieira, considerando princípios que fundamentam os projetos de educação do campo. Por essa razão, assumiram o desafio de construir projetos educativos que ampliem a compreensão crítica da realidade e a produção de conhecimento voltado ao desenvolvimento de outro modelo de sociabilidade no campo, pautado nos princípios da sustentabilidade, justiça social e solidariedade entre os povos.

Nessa perspectiva, as educadoras dedicaram-se à elaboração de alternativas pedagógicas que permitissem o desenvolvimento de diferentes espaços e tempos educativos que favoreçam a interação entre os sujeitos, as trocas de experiências e a construção do conhecimento a partir de diferentes perspectivas de compreender/atuar no mundo. 
Este trabalho foi construído com rigorosidade e clareza quantos aos objetivos e os fins das atividades educativas, bem como quanto aos caminhos que serão percorridos pelos educandos na apropriação dos conceitos necessários à construção de um conhecimento que amplie sua compreensão e inserção crítica no mundo (FREIRE, 2005).

Diante dos desafios implícitos ao trabalho de reorientação das práticas educativas, considerando influência da tradição pedagógica conservadora nas políticas educacionais e nos modelos de formação dos educadores, fizemos a opção de trabalhar inicialmente com os "laboratórios pedagógicos" 6 , que permitem as educadoras e os educandos a vivência coletiva de diferentes instrumentos pedagógicos voltados à construção coletiva do conhecimento e a articulação interdisciplinar dos diferentes conhecimentos e saberes.

Os "laboratórios" construídos a partir da Horta Pedagógica, Viveiro de Mudas e Banco de Sementes tiveram um papel pedagógico relevante, tanto na gestão e planejamento das atividades aproximando as educadoras, os gestores e educandos na construção e o desenvolvimento dos projetos interdisciplinares -, quanto na organização dos educandos e das famílias, atribuindo-Ihes novas demandas associadas à participação coletiva na construção das atividades, na partilha de saberes e trocas de experiências, resultando no fortalecimento do trabalho de cooperação entre os grupos e na produção de novas releituras da realidade a partir dos princípios da sustentabilidade socioambiental e cultural.

A partir dos trabalhos desenvolvidos nos laboratórios e das pesquisas na comunidade, os jovens reafirmavam os vínculos de pertencimento com a terra e com as atividades do campo, resinificando o sentido de ser camponês. A apropriação de conhecimentos que potencializam as estratégias de fortalecimento da agricultura familiar de base agroecológica também exerceu um papel importante neste trabalho de valorização da vida no campo.

O fato de vivenciar na escola um conjunto de atividades associadas com o modo de vida no campo constitui-se num estímulo e incentivo para que os educandos reconheçam a importância deste território no cenário brasileiro, superando os estigmas e preconceitos inerentes à vida dos camponeses, bem como a visão negativa do campo, associada ao atraso e ao subdesenvolvimento, passando a compreendê-lo dentro de outras lógicas de sociabilidade e de outro modelo de produção da vida.

As atividades nos laboratórios, além de oportunizarem uma articulação entre teoria e prática, ampliando a compreensão/apropriação dos conceitos científicos trabalhados nas diferentes áreas do conhecimento, reforçavam também a articulação entre os conhecimentos escolares e os saberes e as

\footnotetext{
6 São ambientes construídos com o propósito de aproximar os estudos desenvolvidos na escola com as experiências sociocultural dos educandos. São estratégias pedagógicas voltadas ao desenvolvimento de atividades que ampliem as articulações entre as práticas sociais e os conhecimentos escolares. Compreendemos os limites deste tipo de trabalho, tendo em vista os princípios políticos da educação do campo; no entanto, reconhecemos sua relevância na construção de alternativas pedagógicas que possibilitem a superação dos modelos de educação bancária instituídos nas escolas do campo.
} 
aprendizagens construídas no ambiente familiar, uma vez que os educandos tinham a oportunidade de apresentar e discutir sobre as experiências e práticas construídas juntos com as família, favorecendo as trocas de experiências e conhecimentos acerca da preservação e cuidado com o maio ambiente, da organização do processo de produção, das dinâmicas de organização políticas e social das atividades desenvolvidas no campo.

Os diálogos interdisciplinares tornaram-se uma prática importante dentro dos estudos realizados a partir das experiências dos laboratórios, numa inter-relação com as experiências do contexto familiar e comunitário. Este trabalho, desenvolvido numa perspectiva interdisciplinar, demandou outro modelo de gestão das práticas educativas capaz de superar as atitudes individualistas das educadoras, priorizando-se o trabalho coletivo e a troca de experiência entre as educadoras, os educandos e a comunidade, com a instituição do planejamento coletivo (LIMA, 2016).

Este trabalho coletivo ampliou as articulações e as trocas de experiências entre as diferentes áreas do conhecimento, a partir dos diálogos entre os educandos acerca dos conteúdos específicos que permeiam as diferentes áreas e são imprescindíveis à compreensão crítica e aprofundada da realidade do campo. Isto resultou na ampliação das capacidades teórico-metodológicas dos educadores em estabelecer os diálogos interdisciplinares com as outras áreas do conhecimento, expandindo as possibilidades de leitura e compreensão da realidade para além das fronteiras disciplinares (FAZENDA, 1999).

A partir dos projetos educativos desenvolvidos, através dos laboratórios e das atividades de pesquisas e imersão crítica na realidade do campo, houve maior envolvimento das famílias nas atividades promovidas pela escola voltadas à discussão da realidade social, política e econômica da comunidade, ampliando as trocas de experiências e conhecimentos.

Com este trabalho, as educadoras e os educandos ampliaram a visão acerca da realidade sociopolítica, econômica e cultural, principalmente com relação às potencialidades e alternativas de desenvolvimento do campo. Nesta perspectiva, as experiências desenvolvidas na escola têm favorecido:

a) reafirmar a viabilidade dos projetos educativos construídos a partir de uma reflexão crítica da realidade, tendo os educandos e as famílias como protagonistas dos processos de produção do conhecimento;

b) evidenciar a capacidade política e pedagógica dos educadores na construção de outras formas de fazer educação em contraposição ao paradigma educacional hegemônico, utilizando-se das contribuições teóricas e metodologias das teorias críticas e das experiências da educação popular construídas historicamente pelos movimentos sociais;

c) demonstrar que é possível construir outras alternativas de produção de conhecimentos que articulem os conhecimentos não acadêmicos e acadêmicos dentro de uma estratégia de 
releitura do mundo, considerando as diferentes matrizes epistemológicas construídas pelos grupos sociais excluídos;

d) transformar os espaços educativos em ambientes de trocas de experiências entre os jovens e de construção coletiva de conhecimentos associados à compreensão de outras formas de sociabilidade diferentes daquela imposta pelo capitalismo global;

e) transformar o ambiente escolar em espaços de vivências de outras experiências de socialização de conhecimentos, valores e saberes - enquanto laboratório de experimentação de outras formas de conhecer e compreender o mundo para além daquilo que é apresentado pelo pensamento capitalista dominante, superando as lógicas de silenciamentos e desperdícios das experiências sociais (SANTOS, 1999).

Diante desse contexto, compreendemos que as práticas educativas implementadas com base nos princípios da educação do campo precisam articular diferentes dispositivos políticos e pedagógicos que favoreçam o exercício da participação ativa dos educandos e a partilha de conhecimentos entre os diferentes sujeitos sociais, através de atividades educativas baseada na cooperação, na resolução de problemas e nos processos de investigação/produção do conhecimento que possibilitem o desenvolvimento da criatividade e criticidade dos jovens.

\section{OS DESAFIOS IMPLÍCITOS NA CONSTRUÇÃO DAS EXPERIÊNCIAS DE EDUCAÇÃO DO CAMPO}

O sistema educacional brasileiro está organizado a partir de um conjunto de diretrizes e princípios políticos e ideológicos atrelado ao ideário neoliberal, portanto, constituído por meio de dispositivos políticos e "técnicos" que atuam na perspectiva de inviabilizar o desenvolvimento de práticas educativas associadas à formação crítica e a emancipação das classes populares.

Neste trabalho de construção deste projeto de educação do campo, constatamos que alguns desafios vivenciados pelas educadoras no contexto das escolas estão vinculados aos modelos de gestão e administração instituídos pelo sistema educacional com o propósito de estabelecer o controle das políticas educacionais e das práticas educativas e curriculares desenvolvidas nas escolas do campo, atrelados à utilização dos textos-guias adotados nas escolas e aos modelos de planejamentos e avaliações padronizados.

Neste processo, as estratégias de controle dos projetos educativos mais comuns nos municípios brasileiros estão associadas às políticas de planejamento de rede, concebidas a partir de uma visão universalista focada na padronização dos projetos educativos, assim como aos sistemas de avaliação 
externas, implementado pela Secretarias estaduais e municipais de Educação, que atuam com o propósito de estabelecer uma vigilância política e ideológica sobre os tipos de conhecimentos, valores e competências desenvolvidas pelos educandos.

Outros desafios estão associados aos princípios políticos e epistemológicos que fundamentam as políticas educacionais nos municípios, associados à "racionalidade técnica"7, que concebe o trabalho educativo dentro da lógica da "educação bancária" voltada ao desenvolvimento de atividades verbalísticas e conteudistas, destituído de significados políticos e culturais para os jovens, devido a sua desvinculação com as práticas sociais e o contexto sócio-históricos dos sujeitos do campo (FREIRE, 2005).

As experiências educativas desenvolvidas a partir da racionalidade técnica estabelecem uma relação mecânica com o conhecimento, concebendo-o como produto pronto e acabado a ser reproduzido nas escolas, sem uma vivência teórico-prática ou uma articulação com os aspectos sociais, políticos e econômicos da sociedade. São projetos concebidos e implementados dentro de uma estratégia de deslocamento do contexto sociopolíticos do campo, portanto, desvinculado das lutas sociais dos camponeses e dos projetos de sociabilidade contra-hegemônicos concebidos pelos movimentos sociais.

Em meio a este jogo político, tivemos o cuidado estabelecer a mediação entre a escola e a secretaria municipal de educação com o propósito de atenuar as imposições pedagógicas, garantindo que as educadoras tivessem a oportunidade de implementar os projetos educativos concebidos a partir das estratégias políticas e pedagógicas discutidas nas Rodas de Diálogos. Com este trabalho de "transgressão pedagógica"8, as educadoras forjaram as condições para a construção de diferentes experiências educativas associadas à produção conhecimentos concebidos a partir das relações dialógicas estabelecidas entre diferentes conhecimentos e contextos sociais e políticos, que permitissem uma releitura do mundo.

Dentro desse processo de "subversão pedagógica", as educadores foram aos poucos apropriandose de outras estratégias de produção do conhecimento associada ao reconhecendo dos diferentes tempos/espaços de formação/aprendizagens, de interação e diálogo entre os educandos, a partir de atividades de intervenção e pesquisa na comunidade, de visitas de estudo, de trabalhos coletivos, entre outros, que permitissem a participação ativa dos jovens e o desenvolvimento de novas aprendizagens a partir da práxis coletiva.

\footnotetext{
7 Para Giroux (1986, p. 225), racionalidade significa "um conjunto específico de pressupostos e práticas sociais que medeiam como o indivíduo ou grupo se relaciona com a sociedade maior. Subjacente a qualquer modo de racionalidade está um conjunto de interesses que definem e limitam como a pessoa reflete sobre o mundo". Desse modo, a racionalidade técnica concebe a produção do conhecimento a partir da quantificação, classificação, fragmentação e simplificação da realidade em estudo, pautado na separação radical entre ser humano/natureza, natureza/cultura, sujeito/objeto, corpo/psique. (SANTOS, 1999).

8 "As transgressões pedagógicas podem ser interpretadas como tentativas individuais ou coletivas de driblar, nos regulados tempos escolares, a hegemonia dos objetos, a redução das relações pedagógicas a relações de objeto (ARROYO, 2000, p. 139). Estão associadas às estratégias de implementação de projetos educativos se distanciam das orientações políticas das secretarias de educação, resgatando a autonomia pedagógica da escola na implementação de projetos que atendam aos interesses políticos concebidos coletivamente pela comunidade.
} 
Nos processos de avaliação coletiva do trabalho, contatamos que as educadoras convivem, no âmbito das escolas do campo, com uma cultura escolar e profissional constituída a partir de uma tradição pedagógica conservadora, permeada por rituais e normas que limitam as transformações das práticas educativas e curriculares. Associada a isto, temos também as deficiências relacionadas à frágil formação teórica e política das educadoras, condicionadas aos aspectos didáticos e pedagógicos, desvinculada de uma compreensão mais ampla acerca dos fundamentos políticos e filosóficos que orientam os projetos educativos e do modelo de sociabilidade que estas experiências de educação estão vinculadas.

Essa fragilidade percebida na área da formação trouxe desafios à construção dos projetos de educação do campo: primeiro, devido às limitações destes profissionais na construção de uma leitura crítica da realidade e dos condicionantes políticos e ideológicos que influenciam o fazer educativo neste território; segundo, a ausência desta compreensão ampla acerca da realidade do campo limita a capacidade de atuação destes profissionais na elaboração de projetos educativos comprometidos com a transformação social.

Além disso, os profissionais da educação apresentam lacunas na formação científica relacionadas ao domínio dos conceitos básicos e das categorias centrais das diferentes áreas do conhecimento. Por essa razão, são evidentes as dificuldades enfrentadas na construção de uma leitura interdisciplinar das questões teórico-práticas e dos problemas socioculturais, políticos, econômicos e ambientais vivenciados pelos educandos e a comunidade a partir das atividades de pesquisas e imersão na realidade do campo. Esta situação se agrava também nas escolas do campo na medida em que temos uma parte significativa das educadoras atuando fora das suas áreas de formação.

Em meio a esse movimento político, buscamos construir formas alternativas de pensar/fazer a educação do campo no contexto do semiárido dentre outros marcos teóricos que possibilitam aos educandos e educadores o desenvolvimento da criatividade e da criticidade, construindo experiências outras que apontassem na perspectiva da inovação pedagógica, dentro daqueles princípios políticos e pedagógicos que compunham a proposta de uma educação crítica e emancipadora.

\section{CONSIDERAÇÕES FINAIS}

As políticas educacionais desenvolvidas na maioria das escolas do campo no Brasil ainda são instituídas numa perspectiva urbanocêntrica, que desconsidera as especificidades sócio-históricas e culturais dos povos do campo, bem como os conhecimentos e saberes construídos a partir das práticas sociais vivenciadas nesse território. Além disso, os projetos educativos são construídos a partir das ideologias capitalistas, que favorecem uma compreensão do campo atrelada ao modelo de desenvolvimento 
proposto pelo agronegócio e o mercado financeiro, em detrimento do apoio à agricultura familiar e aos sistemas de produção agroecológicos.

Contrapondo-se a este modelo de educação, os movimentos sociais têm empreendidos esforços no sentido de fomentar uma política de educação do campo concebida pelos camponeses, a partir da realidade sociopolítica, econômica e cultural deste território, capaz de reconhecer os conhecimentos historicamente associados à construção de um projeto de desenvolvimento pautado na sustentabilidade, na justiça social e a organização coletiva e cooperativa das comunidades.

A partir das reflexões desenvolvidas nas Rodas de Diálogo, constatamos que, apesar dos dispositivos de controle instituídos pelo sistema educacional, associado às estratégias de padronização e homogeneização dos projetos educativos, foi possível construir alternativas políticas e pedagógicas que permitissem à implementação de práticas educativas interdisciplinares, numa perspectiva emancipadora, voltadas à construção coletiva do conhecimento. Por meio de um processo de "transgressão pedagógica", construímos diferentes atividades de estudos coletivos, pesquisas, intervenções e mobilizações sociais na comunidade, entre outras, focadas no protagonismo dos/as jovens e na compreensão das possibilidades de transformação social.

Neste trabalho de reorientação das práticas educativas, a participação ativa dos educandos e da comunidade foi fundamental para que escola pudesse avançar na construção do projeto de educativos baseados nos princípios da educação do campo, garantindo o apoio político necessário para que as educadoras pudessem ousar na construção de outros caminhos teóricos e metodológicos, baseado nos estudos e nas pesquisas sobre a realidade do campo, nas trocas de experiências entre a escola e a comunidade, que favorecessem a construção de conhecimentos voltados à construção de outro olhar sobre o campo e sobre as possibilidade de vida neste território.

Nessa perspectiva, as parcerias entre as escolas, as comunidades e os movimentos sociais do campo são imprescindíveis para a consolidação dos projetos de educação do campo, tendo em vista os desafios políticos e pedagógicos que precisam ser superados cotidianamente no sentido de consolidar este modelo de educação comprometido com a construção de outras alternativas de desenvolvimento, que se contrapõem ao agronegócio, centrado na concentração de riquezas, na exploração dos trabalhadores e na destruição do biodiversidade.

\section{REFERÊNCIAS}

ARROYO, Miguel G. Pedagogias em movimento: o que temos a aprender dos Movimentos Sociais? Currículo sem Fronteiras, v.3, n. I, p. 28-49, jan./jun. 2003.

ARROYO, Miguel G. Ofício de Mestre: imagens e auto-imagens. Petrópolis: Vozes, 2000. 
BRASIL. Conselho Nacional de Educação. Diretrizes Operacionais para a Educação Básica nas Escolas do Campo. Resolução CNE/CEB n I, de 3 de abril de 2002. Brasília, Diário Oficial [da] República Federativa do Brasil, 9 de abril de 2002. Seção I, p. 32.

BRASIL. Referências para uma política nacional de educação do campo: caderno de subsídios. Brasília: MEC/SECAD, 2005.

BRASIL. Educação do campo: diferenças mudando paradigmas. Secretaria de Educação Continuada, Alfabetização e Diversidade - SECAD/MEC, 2007.

CALDART, Roseli Salete. Pedagogia do Movimento Sem Terra: escola é mais do que escola. Petrópolis: Vozes, 2000.

CEAAL. Conselho de Educação de Adultos da América Latina. Educação Popular para uma Democracia com Cidadania e Equidade, Buenos Aires, 1994.

FAZENDA, Ivani C. A. Interdisciplinaridade: história, teoria e pesquisa. Campinas: Papirus, 1999.

FERNANDES, Bernardo M. Os campos da Pesquisa em Educação do Campo: espaço e território como categorias essenciais. In: Molina, Mônica C. (org.). Educação do Campo e Pesquisa: questões para reflexão. Brasília: Ministério do Desenvolvimento Agrário, 2006.

FRANCO, Maria Amélia S. Pedagogia da Pesquisa-Ação. Educação e Pesquisa, São Paulo, v. 3 I , n. 3, p. 483-502, set./dez. 2005.

FREIRE, Paulo. Pedagogia do oprimido. 17 ed. Rio de Janeiro: Paz \& Terra, 2005.

FREIRE, Paulo. Conscientização: teoria e prática da libertação, uma introdução ao pensamento de Paulo Freire. São Paulo: Moraes, 1980.

FREIRE, Paulo. Pedagogia da Esperança: Um reencontro com a Pedagogia do Oprimido. Rio de Janeiro, Paz e Terra, 1992.

FREITAS, Helana Célia de Abreu. Rumos da Educação do Campo. Em Aberto, Brasília, v. 24, n. 85, p. 35-49, abr. 2011.

GIROUX, Henri A. Teoria crítica e resistência em educação. Petrópolis, RJ: Vozes, 1986.

LEAL, Victor Nunes. Coronelismo, enxada e voto (O município e o regime representativo no Brasil). $3^{a}$ Ed Rio de Janeiro: Nova Fronteira, 1997.

LIMA, Elmo de S. Formação continuada de educadores/as: as possibilidades de reorientação do currículo. Curitiba: CRV, 2015.

LIMA, Elmo de S. A organização interdisciplinar do currículo nas escolas do campo: os dilemas políticos e pedagógicos. In: LIMA, Elmo de S.; MELO, Keylla Rejane A. (Org.). Educação do campo: reflexões políticas e teórico-metodológicas. Teresina - PI: EDUFPI, 2016, p. 65-90.

PISTRAK, Moisey M. Fundamentos da escola do Trabalho: uma pedagogia social. São Paulo: Expressão Popular, 2003.

SANTOS, Boaventura de S. Pela Mão de Alice: o social e o político na pós-modernidade. São Paulo: Cortez, 1999. 
SILVA, Maria do S. Da raiz à flor: produção pedagógica dos movimentos sociais e a escola do campo. In: MOLINA. Mônica Castagna (Org.). Educação do campo e pesquisa: questões para reflexão. Brasília: Ministério do Desenvolvimento Agrário, p. 60-93, 2006.

\section{COMO CITAR ESSE ARTIGO}

\section{Associação Brasileira de Normas Técnicas (ABNT)}

LIMA, Elmo de Souza. Educação do campo no contexto do semiárido: movimentos de resistência e transgressão pedagógica. Debates em Educação, Maceió, v. 12, p. 193-212, dez. 2020. ISSN 2175 6600. Disponível em: https://www.seer.ufal.br/index.php/debateseducacao/article/view//0076. Acesso em: dd mmm. aaaa.

\section{American Psychological Association (APA)}

Lima, E. (2020). Educação do campo no contexto do semiárido: movimentos de resistência e transgressão pedagógica. Debates em Educação, 12(Esp2), 193-212. doi: https://doi.org/I0.28998/2175-6600.2020v I2nEsp2p I93-2I2 